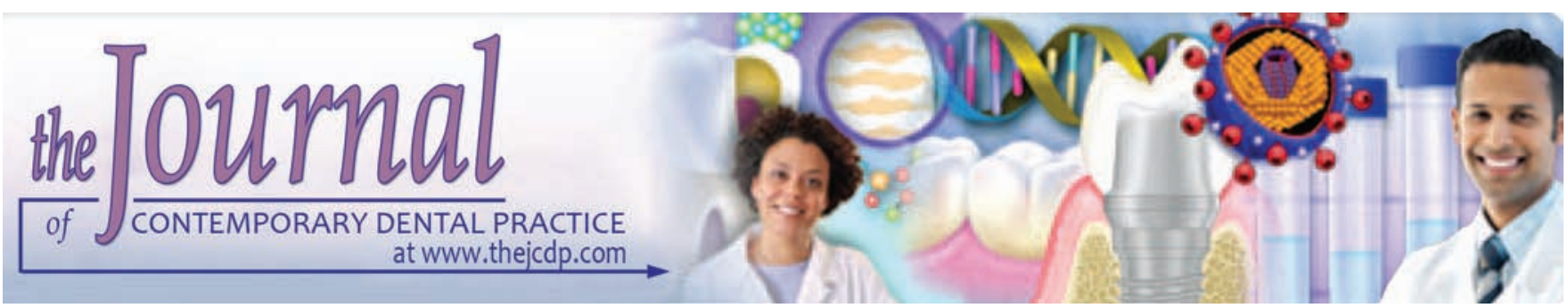

\title{
Measurement of Crestal Cortical Bone Thickness at Implant Site: A Cone Beam Computed Tomography Study
}

\author{
${ }^{1}$ Ajai Gupta, ${ }^{2}$ Suprabha Rathee, ${ }^{3}$ Jaihans Agarwal, ${ }^{4}$ Renu B Pachar
}

\begin{abstract}
Aim: Dental implants have emerged as a new treatment modality for the majority of patients complaining of missing teeth. Bone quantity and bone quality are among various factors which ensure the longevity of dental implant in the patient's mouth. The assessment of cortical bone thickness of the outer layer and the cancellous bone density by cone beam computed tomography (CBCT) has proved beneficial for the patient. This study aimed at presurgical measurement of crestal bone thickness at various implant sites using CBCT images.
\end{abstract}

Materials and methods: This study was conducted in the Department of Prosthodontics in the year 2015. It included 218 patients who wanted to replace missing teeth. Patients were subjected to CBCT scan using NewTom CBCT machine operating at $120 \mathrm{kVp}$ and $5 \mathrm{~mA}$ with a resolution of $0.1 \times 0.1 \times 0.1 \mathrm{~mm}^{3}$. New Net Technologies (NNT) software with a slice thickness of $0.1 \mathrm{~mm}$ was used in this study. A total of 780 implant sites were identified on images of 218 patients. In all patients, the measurement of crestal bone thickness in the region of implant site was performed with NNT software. The buccolingual measurement of crestal bone was done in cross sections obtained after CBCT.

Results: Out of 218 patients, males were 110 and females were 108. The difference between gender was nonsignificant $(p>0.05)$. Out of 780 implant sites, 370 were in the maxilla and 410 were in mandible. The difference was nonsignificant $(p>0.05)$. Out of 780 implant sites, 210 were in anterior maxilla and 160 were in the posterior maxilla. Totally, 235 sites were in anterior mandible and 175 were in the posterior mandible.

\footnotetext{
1,2Department of Prosthodontics, Crown and Bridge, Inderprastha Dental College \& Hospital, Ghaziabad, Uttar Pradesh, India

${ }^{3}$ Department of Conservative Dentistry and Endodontics, Shree Bankey Bihari Dental College and Research Centre, Ghaziabad Uttar Pradesh, India

${ }^{4}$ Department of Prosthodontics, Maharaja Ganga Singh Dental College \& Research Centre, Sri Ganganagar, Rajasthan, India

Corresponding Author: Ajai Gupta, Department of Prosthodontics, Crown and Bridge, Inderprastha Dental College \& Hospital, Ghaziabad, Uttar Pradesh, India, Phone: +919811514226, e-mail: drajaigupta2003@yahoo.co.in
}

The distribution was nonsignificant $(p=0.15)$. The mean crestal bone thickness in anterior maxilla was $0.82 \mathrm{~mm}$, in posterior maxilla was $0.76 \mathrm{~mm}$, in anterior mandible was $1.08 \mathrm{~mm}$, and in posterior mandible was $1.18 \mathrm{~mm}$. The difference among regions was significant $(p=0.01)$.

Conclusion: The highest thickness of cortical bone was observed in posterior mandible followed by anterior mandible, anterior maxilla, and posterior maxilla. Thus, considering the less cortical thickness in the posterior maxillary region, the implant placement should be done with proper attention.

Clinical significance: Dental implant is the need of the hour. It is beneficial to patients in terms of longer survival rates. With $\mathrm{CBCT}$, all measurements, such as bone quality and quantity have become easy because of three-dimensional nature. This has proved to be beneficial in the analysis of cortical bone thickness as well as measuring the distance from anatomical structures.

Keywords: Bone quality, Cone beam computed tomography, Implant.

How to cite this article: Gupta A, Rathee S, Agarwal J, Pachar RB. Measurement of Crestal Cortical Bone Thickness at Implant Site: A Cone Beam Computed Tomography Study. J Contemp Dent Pract 2017;18(9):785-789.

Source of support: Nil

Conflict of interest: None

\section{INTRODUCTION}

Removable or fixed partial dentures were used to replace missing teeth in the past. With new advancement in the field to prosthetic dentistry, dental implants have emerged as new treatment modality for the majority of patients complaining of missing teeth and are expected to play a significant role in oral rehabilitation in the future. ${ }^{1}$

Apart from high demand of dental implants among patients, there are many related factors affecting the success of dental implants. The first group of factors is host-related factors on which success rate of the implant depends, such as age and gender of the patient, oral hygiene status, and 
deleterious habits, such as smoking and various systemic diseases. The second group is implant placement siterelated factors, such as implant position in jaw, quality and quantity of bone in which implant has to be placed. Surgery-related factors, such as angulation and direction of the implant in the arch and the efficiency of an operator constitute the third group. The fourth group is implant fixture-related factors, such as length and diameter of implant, surface roughness, and microstructure and macrostructure of an implant fixture. The fifth group is factors related to implant prostheses, such as prosthesis type, retention method, and occlusal scheme. ${ }^{2}$

Bone quantity and bone quality are among various factors that ensure the longevity of dental implant in the patient's mouth. Various studies have revealed that implants placed in mandibular arch have high survival rate than those placed in maxillary arch. Hence, presurgical evaluation of bone is mandatory to assess quality and quantity of bone in implant site. ${ }^{3,4}$

Earlier, intraoral periapical radiographs, ultrasonographs, and panoramic radiographs were the choice for evaluation of quantity and quality of bone since all these methods lack precise information as two-dimensional (2D) nature of imaging modalities. This shortcoming has been overcome by newer diagnostic aids, such as CBCT due to its three-dimensional (3D) nature. The assessment of cortical bone thickness of the outer layer and the cancellous bone density by CBCT has proved beneficial for the patients. ${ }^{5}$

Considering all these factors, this study aimed at presurgical measurement of crestal bone thickness at various implant sites using CBCT images.

\section{MATERIALS AND METHODS}

This study was conducted in the Department of Prosthodontics in 2015. It included 218 patients who wanted to replace missing teeth. All were informed regarding the study, and written consent was obtained. Patient's information, such as name, age, gender, and missing teeth was recorded.

Patients were subjected to CBCT scan using NewTom CBCT machine operating at $120 \mathrm{kVp}$ and $5 \mathrm{~mA}$ with a resolution of $0.1 \times 0.1 \times 0.1 \mathrm{~mm}^{3}$. New Net technologies software with a slice thickness of $0.1 \mathrm{~mm}$ was used in this study. A total of 780 implant sites were identified on images of 218 patients.

In all patients, the measurement of crestal bone thickness in the region of implant site was performed with NNT software. The measurement of thickness of crestal bone was done in sagittal cross sections obtained after CBCT. Measurements were done in four sites: Anterior maxilla (Fig. 1), anterior mandible (Fig. 2), posterior maxilla (Fig. 3), and posterior mandible (Fig. 4). The measurements were recorded in millimeters. Results thus obtained were subjected to statistical analysis. A p-value $<0.05$ was considered significant.

\section{RESULTS}

Table 1 shows that out of 218 patients, males were 110 and females were 108. The difference among gender was nonsignificant ( $p>0.05)$. Graph 1 shows that out of 780 implant sites, 370 were in maxilla and 410 were in mandible. The difference was nonsignificant $(p>0.05)$. Graph 2 shows that out of 780 implant sites, 210 were in anterior maxilla and 160 were in posterior maxilla; 235 sites were in anterior mandible and 175 were in the posterior mandible. The distribution was nonsignificant $(p=0.15)$. Table 2 shows that mean of crestal bone thickness in anterior maxilla was $0.82 \mathrm{~mm}$, in posterior maxilla was $0.76 \mathrm{~mm}$, in anterior mandible was $1.08 \mathrm{~mm}$, and in posterior mandible was $1.18 \mathrm{~mm}$. The difference among regions was significant $(\mathrm{p}=0.01)$.

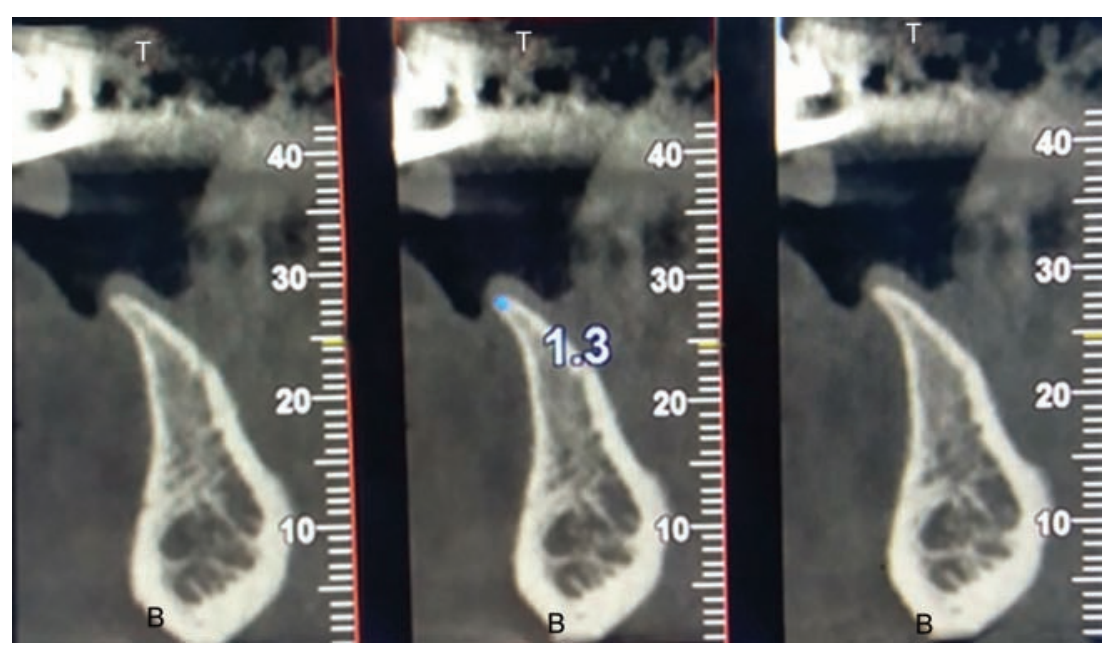

Fig. 1: Measurement of crestal cortical bone thickness in anterior maxillary implant site 


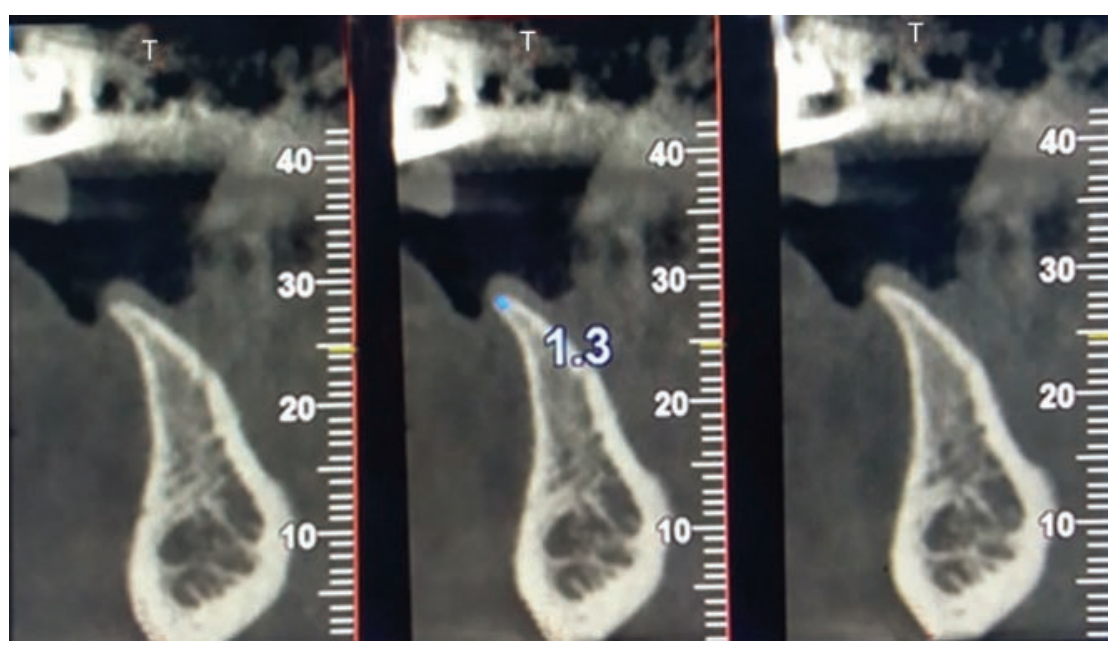

Fig. 2: Measurement of crestal cortical bone thickness in anterior mandibular implant site

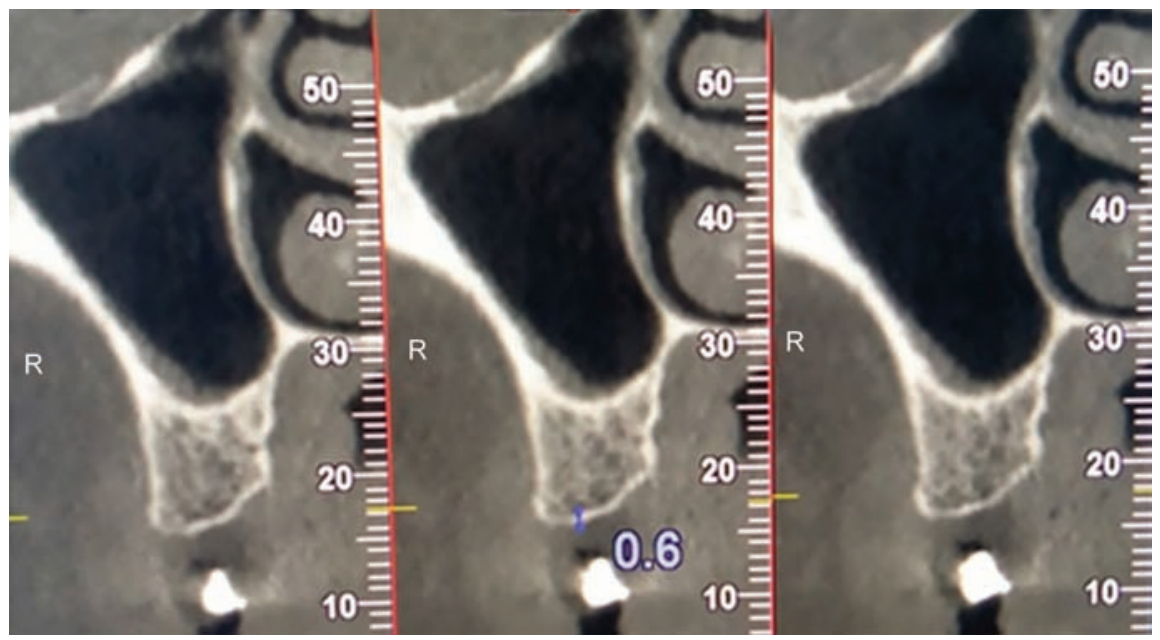

Fig. 3: Measurement of crestal cortical bone thickness in posterior maxillary implant site

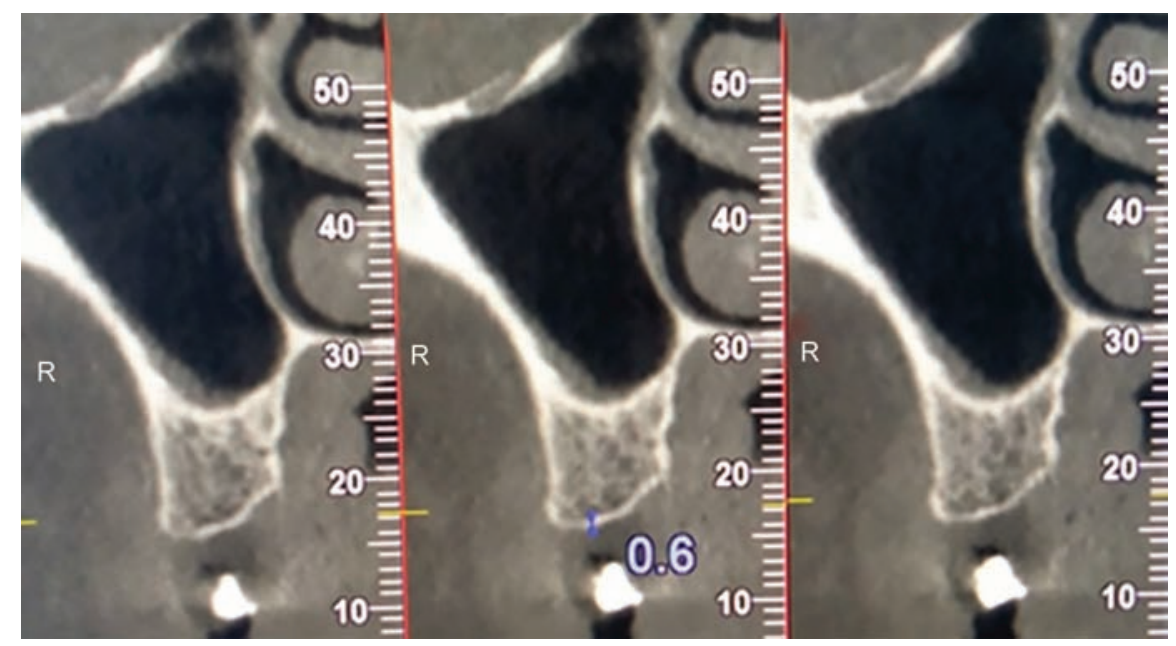

Fig. 4: Measurement of crestal cortical bone thickness in posterior mandibular implant site 
Table 1: Distribution of patients

\begin{tabular}{lll}
\hline & Total -218 & \\
\hline Males & Females & $p$-value \\
\hline 110 & 108 & 1 \\
\hline
\end{tabular}

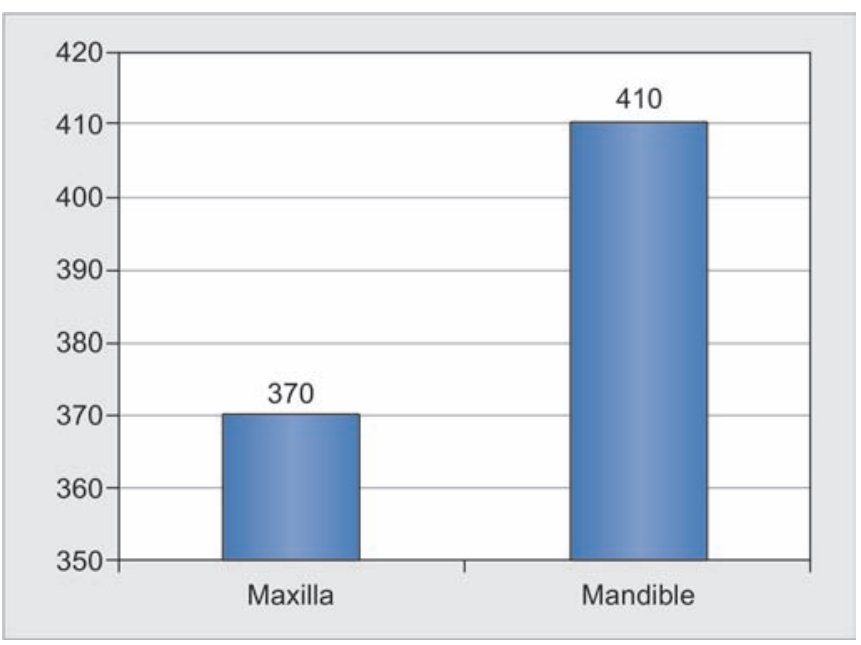

Graph 1: Distribution of implant sites

\section{DISCUSSION}

Dental implants have become the need of the hour for replacement of missing teeth. The longevity of implants and no need for adjacent tooth preparation as in the case of fixed partial denture, etc., have increased the demand for implants among patients. The success of implant depends on osseointegration of bone with dental implants. Better the osseointegration, more is the survival rate of the implant. It further depends on bone quality and amount of bone present. ${ }^{6}$

This study was conducted to assess crestal cortical bone thickness at implant site using CBCT. In our study, there were 780 implant sites in 218 patients. Males were 110 and females were 108 in number. Maximum implant sites were seen in mandible as compared with maxilla. Our results are in agreement with the results of Hashim et al. ${ }^{7}$ In their study also maximum implant sites were seen in mandible. We found that maximum implant sites were seen in anterior maxilla (280) followed by anterior mandible (235), posterior mandible (175), and posterior maxilla (160). Our results are in agreement with e results of Schnitman et al. ${ }^{8}$ The aim of our study is to measure the width and not the number of implant sites, so the result should be related to a width only.

Lekholm and Zarb ${ }^{9}$ in their study classified bone quality and quantity into four types using 2D X-ray images. Type I bones were composed of homogeneous compact bone, type II bones comprised a thick layer of compact bone surrounding a core of dense trabecular bone, type III bones consisted of a thin layer of cortical bone surrounding a core of dense trabecular bone, and
Table 2: Crestal bone thickness in all regions

\begin{tabular}{lllll}
\hline Region & $\begin{array}{l}\text { Mean } \pm S D \\
(\mathrm{~mm})\end{array}$ & $\begin{array}{l}\text { Maximum } \\
(\mathrm{mm})\end{array}$ & $\begin{array}{l}\text { Minimum } \\
(\mathrm{mm})\end{array}$ & $p$-value \\
\hline Anterior maxilla & $0.82 \pm 0.32$ & 1.96 & 0.14 & 0.01 \\
Posterior maxilla & $0.76 \pm 0.28$ & 1.78 & 0.13 & \\
Anterior mandible & $1.08 \pm 0.30$ & 2.12 & 0.41 & \\
Posterior mandible & $1.18 \pm 0.48$ & 3.60 & 0.38 & \\
\hline
\end{tabular}

SD: Standard deviation

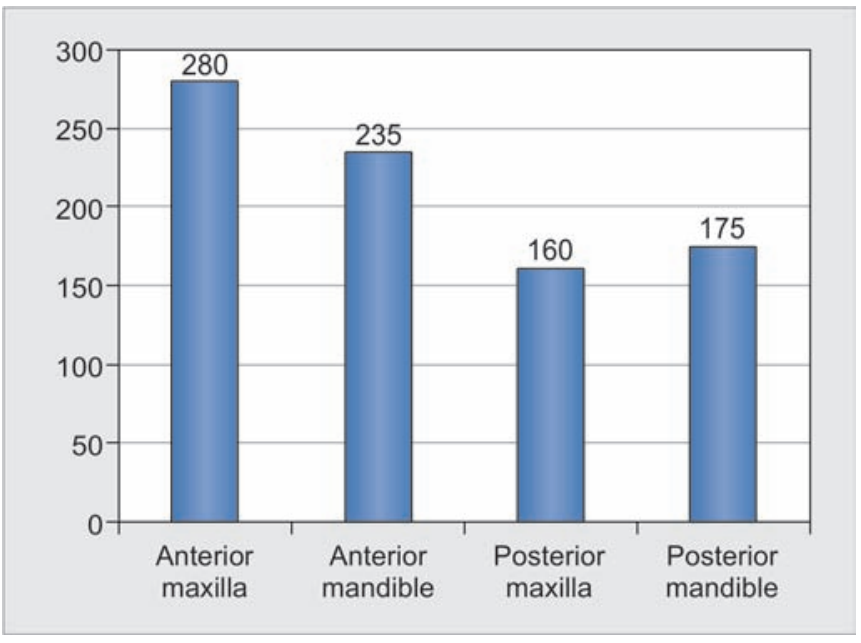

Graph 2: Distribution of implant sites in both jaws

type IV bones exhibited a thin layer of cortical bone surrounding a core of low-density trabecular bone of poor strength. However, this method was completely based on the amount of compact bone with trabeculation. This method lacks exact analysis of bone quantity and bone quality as this utilized 2D images only. Moreover, being $2 \mathrm{D}$ in nature, distortion and overlapping of adjacent structures were also common. ${ }^{10}$

With the advent of 3D CBCT, the analysis of bone quality and quantity has greatly improved because it had low patient exposure as compared with computed tomography (CT) scan with high resolution. ${ }^{11}$ A study conducted by Sumer et $\mathrm{al}^{12}$ revealed that CBCT is the choice of diagnostic modality for measurement of palatal bone thickness at implant sites.

Miyamoto et $\mathrm{al}^{13}$ in their study used CT scan for analysis with a resolution of $400 \mu \mathrm{m}$, whereas in our study, the CBCT scans had a resolution of $100 \mu \mathrm{m}$. Sugiura et $\mathrm{al}^{14}$ in their study examined cortical bone thickness in posterior mandible and found a thickness of $1.5 \pm 0.7$ [mean \pm standard deviation (SD)], whereas in this study, we found thickness of $1.18 \pm 0.48$ (mean \pm SD) in posterior mandible. Similarly, Deguchi et $\mathrm{al}^{15}$ in their study evaluated the cortical bone thickness and found more thickness in posterior mandible as compared with our study.

In this study, the crestal cortical bone thickness at implant sites in various regions was as follows: Posterior mandible $(1.18 \pm 0.48 \mathrm{~mm})$, anterior mandible $(1.08 \pm$ 
$0.30 \mathrm{~mm})$, anterior maxilla $(0.82 \pm 0.32 \mathrm{~mm})$, and posterior maxilla $(0.76 \pm 0.28 \mathrm{~mm})$. We found that thinnest bone was seen in posterior maxillary implant site, owing to the presence of maxillary sinus. Thus, placement of implants in posterior maxilla should be done with care because of less cancellous bone density in this region and proximity of floor of maxillary sinus. ${ }^{16}$ However, Gerlach et $\mathrm{al}^{17}$ in their study found more cortical bone thickness on mandibles using CBCT study as compared with our study. Similarly, Baumgaertel and Hans ${ }^{18}$ measured the buccal cortical plate thickness for mini-implant placement and found that it is more in the anterior mandible. Artzi et $\mathrm{al}^{19}$ in their study evaluated the survival rate of 248 dental implants and found that the highest survival rate was seen in anterior mandible and the lowest in posterior maxilla.

\section{CONCLUSION}

The CBCT is efficient in assessing cortical bone thickness at implant site. The disadvantages of low resolution and distortion of image by 2D have significantly reduced. The highest thickness of cortical bone was observed in posterior mandible followed by anterior mandible, anterior maxilla, and posterior maxilla. Thus, considering the less cortical thickness in the posterior maxillary region, the implant placement should be done with proper attention.

\section{REFERENCES}

1. Brunski JB, Puleo DA, Nanci A. Biomaterials and biomechanics of oral and maxillofacial implants: current status and future developments. Int J Oral Maxillofac Implants 2000 Jan-Feb;15(1):15-46.

2. Hsu JT, Huang HL, Tsai MT, Wu AY, Tu MG, Fuh LJ. Effects of the 3D bone-to-implant contact and bone stiffness on the initial stability of a dental implant: Micro-CT and resonance frequency analyses. Int J Oral Maxillofac Surg 2013 Feb;42(2):276-280.

3. Esposito M, Hirsch JM, Lekholm U, Thomsen P. Biological factors contributing to failures of osseointegrated oral implants. (II). Etiopathogenesis. Eur J Oral Sci 1998 Jun;106(3):721-764.

4. Cakarer S, Selvi F, Can T, Kirli I, Palancioglu A, Keskin B, Yaltirik M, Keskin C. Investigation of the risk factors associated with the survival rate of dental implants. Implant Dent 2014 Jun;23(3):328-333.

5. Huang HL, Chang YY, Lin DJ, Li YF, Chen KT, Hsu JT. Initial stability and bone strain evaluation of the immediately loaded dental implant: an in vitro model study. Clin Oral Implants Res 2011 Jul;22(7):691-698.
6. Geckili O, Bilhan H, Geckili E, Cilingir A, Mumcu E, Bural C. Evaluation of possible prognostic factors for the success, survival, and failure of dental implants. Implant Dent 2014 Feb;23(1):44-50.

7. Hashim D, Cionca N, Courvoisier DS, Mombelli A. A systematic review of the clinical survival of zirconia implants. Clin Oral Investig 2016 Sep;20(7):1403-1417.

8. Schnitman PA, Rubenstein JE, Whörle PS, DaSilva JD, Koch GG. Implants for partial edentulism. J Dent Educ 1988 Dec;52(12):725-736.

9. Lekholm, U.; Zarb, GA. Patient selection and preparation. In: Brånemark PI, Zarb GA, Albrektsson T, editors. Tissueintegrated prostheses: osseointegration in clinical dentistry. Chicago (IL): Quintessence; 1985. p. 199-209.

10. Ye N, Jian F, Xue J, Wang S, Liao L, Huang W, Yang X, Zhou Y, Lai W, Li J, et al. Accuracy of in-vitro tooth volumetric measurements from cone-beam computed tomography. Am J Orthod Dentofacial Orthop 2012 Dec;142(6):879-887.

11. Adell R, Lekholm U, Rockler B, Brånemark PI. A 15-year study of osseointegrated implants in the treatment of the edentulous jaw. Int J Oral Surg 1981 Dec;10(6):387-416.

12. Sumer AP, Caliskan A, Uzun C, Karoz TB, Sumer M, Cankaya S. The evaluation of palatal bone thickness for implant insertion with cone beam computed tomography. Int J Oral Maxillofac Surg 2016 Feb;45(2):216-220.

13. Miyamoto I, Tsuboi $Y$, Wada E, Suwa H, Iizuka T. Influence of cortical bone thickness and implant length on implant stability at the time of surgery - clinical, prospective, biomechanical, and imaging study. Bone 2005 Dec;37(6):776-780.

14. Sugiura T, Yamamoto K, Kawakami M, Horita S, Murakami K, Kirita T. Influence of bone parameters on peri-implant bone strain distribution in the posterior mandible. Med Oral Patol Oral Cir Bucal 2015 Jan;20(1):e66-e73.

15. Deguchi T, Nasu M, Murakami K, Yabuuchi T, Kamioka H, Takano-Yamamoto T. Quantitative evaluation of cortical bone thickness with computed tomographic scanning for orthodontic implants. Am J Orthod Dentofacial Orthop 2006 Jun;129(6):721.e7-e12.

16. Klintström E, Smedby O, Moreno R, Brismar TB. Trabecular bone structure parameters from $3 \mathrm{D}$ image processing of clinical multi-slice and cone-beam computed tomography data. Skeletal Radiol 2014 Feb;43(2):197-204.

17. Gerlach NL, Meijer GJ, Borstlap WA, Bronkhorst EM, Bergé SJ, Maal TJJ. Accuracy of bone surface size and cortical layer thickness measurements using cone beam computerized tomography. Clin Oral Implants Res 2013 Apr;24(4):793-797.

18. Baumgaertel S, Hans MG. Buccal cortical bone thickness for mini-implant placement. Am J Orthod Dentofacial Orthop 2009 Aug;136(2):230-235.

19. Artzi Z, Carmeli G, Kozlovsky A. A distinguishable observation between survival and success rate outcome of hydroxyapatite-coated implants in 5-10 years in function. Clin Oral Implants Res 2006 Feb;17(1):85-93. 